for other points of the curve (in Fig. 2), we shall obtain data for the study of the thermal interchange between the sea and the air : if the temperature of the former is greater than that of the air, there will be a more rapid cooling of the water; conversely, the cooling down will be retarded. From such observations can be deduced the law of thermal interchange, a law of very great importance for geophysical problems.

A great number of observations have been made by me from the Black Sea, over the Mediterranean, Red Sea, Indian Ocean, to the China and Japan Seas, from July 1925 to March 1927. The results of the measurements of the evaporation and thermal interchange will appear in Gerlands Beiträge zur Geophysik. The instrument used for these measurements was suspended on Cardan-rings, as is shown in Fig. 1, $A$ is the anemometer, placed on the same level with the water in the vessel.

With an analogous instrument one can measure the evaporation of water immediately from the level of the sea or of the lake; in this case it must float in the water so that the edges of the Dewar vessel just touch the water-level. Thus it is possible to find the connexion between the evaporation from a vessel on board a ship and the evaporation in natural conditions.

It is understood, of course, that such experiments can be made only when the water is sufficiently calm.

Physical Institution, WAS. SHOULEJKIN.

3 Miusskaja 3, Moscow.

Transmission of Heat through a Brick Wall.

THE letter on "Solar Radiation and Diathermancy" in NATURE, Mar. 26, 460, seems worthy of comment. Radiation, which Mr. Dufton thinks must be called into account to explain the rapid transmission of heat through a brick wall as shown by his curves, is, of course, a possible factor in heat conduction. It appears to us, however, an unlikely one in this case, so we have tried some calculations on the transmission to see if it cannot be explained on the basis of ordinary conduction, assuming reasonable values for the thermal constants.

Fortunately for the purposes of calculation a ladder has, by its shadow, impressed upon the curves at one point a very fair sine periodicity (period $T$ about 1650 seconds), and the velocity $V$ with which the maximum or minimum phase penetrates into the material can be computed. The thermal diffusivity (conductivity divided by product of specific heat and density) is connected with $V$ and $T$ in this case by the relation $V^{2} T / 4 \pi . \quad V$ may be determined by plotting maxima and minima against time. The points up to a quarter of the whole thickness give a very fair straight line, and even the total thickness curve gives points on the same line if a reasonable assumption is made in identifying corresponding maxima. The half thickness curve does not fit at all, but little weight is given these two latter curves as, strictly speaking, the simple theory does not apply so well to them.

The average velocity comes out $0.0072 \mathrm{~cm} . / \mathrm{sec}$., which gives a diffusivity of 0.0068 c.g.s. units. This is within the range 0.005 to 0.007 usually found for brick. Accordingly we feel that, while there are certain things about some of the curves which require further explanation, there is no good reason for bringing in other than ordinary conductivity considerations in accounting for the penetration.

L. R. INGERSOLL. JOHN BARDEEN.

University of Wisconsin,

Madison, Wis., May 7.

\section{A New Type of Primary Cell.}

WITH reference to the new type of primary cell described by Jindal (NATURE, April 30, p. 639), a description of a two-fluid 'oxidation' cell recently constructed by me may prove interesting.

Zinc, in a saturated solution of ammonium sulphate, and carbon, in an acidified solution of potassium permanganate, form the constituents. In order to maintain the permanganate solution saturated, a layer of the crushed salt is placed at the bottom of the containing vessel.

This cell has an E.M.F. of $2 \cdot 16$ volts, with an internal resistance of $\mathbf{0 . 5} \mathrm{ohm}$ approximately, for currents varying from $0 \cdot 6$ to $0 \cdot 2$ ampere.

On a simple test, with continuous discharge for twenty hours, the output remained constant for eight hours at 0.3 ampere, afterwards decreasing to 0.2 ampere.

At the conclusion of the test the initial E.M.F. was quickly reached.

Practically no polarisation occurs, and the amount of zinc dissolved is inappreciable.

The cell possesses many advantages over the Daniell elements used in laboratories, and should prove useful, in a modified form, as a source of high tension supply in wireless work.

Department of Physics,

D. R. BARBER.

University College, Exeter, May 13.

\section{The Industrial Revolution.}

Miss BueR's letter in NATURE of May 7 removes the difficulties which I felt in accepting the reviewer's statement that the rise and population in England after 1750 was due to the introduction of inoculation and a consequent decline in infant mortality.

I am, however, mainly interested in the industrial history of Great Britain in the first half of the eighteenth century, and here I still think that Miss Buer has underestimated the influence of the Colonial trade upon developments in the west of England. In her chapter on commerce Miss Buer says that "Bristol and Norwich were stationary and Liverpool had hardly begun to be." The chroniclers of Bristol (Nicholls and Taylor, for example) do not support this statement. Bristol, it would appear, had been growing in importance long before 1750 , and this prosperity had extended beyond the City walls. In 1756, Dean Tucker estimated that the proportion of iron manufacturers-that is, smiths to iron-makers-was two thousand to one. The former were using largely American bar iron, but the iron industry had already moved from the Weald to the west to be in a position to supply this growing market. Hence it is probable that there was in the first half of the eighteenth century a considerable redistribution of population in Great Britain-some depopulation by the southern counties being more than offset by an increase in the western area.

Old Houso,

E. WYNDham HuLme.

East St., Littlehampton.

\section{A Gonvenient and Rapid Method of Sampling.}

IN a recent investigation carried out by the writers, with Mr. E. B. Wedmore (see paper read before the Institution of Electrical Engineers on April 7, entitled "A Contribution to the Study of the Number of Tests required to establish the Rupturing Capacity of an Oil Circuit Breaker"), it was desirable to

No. 3007, VoL. 119] 